\title{
Perspective: The Potential Role of Vasoactive Intestinal Peptide in treating COVID-19
}

\author{
Jonathan C. Javitt, MD, MPH${ }^{1}$ \\ ${ }^{1}$ Johns Hopkins University
}

May 13, 2020

\section{Keywords}

Aviptadil, Vasoactive Intestinal Peptide, VIP, SARS-CoV-2, COVID-19, Corona Virus, Acute Respiratory Distress Syndrome, ARDS, Acute Lung Injury, ALI, surfactant, Alveolar Type II, ATII

\section{Perspective: The Potential Role of Vasoactive Intestinal Peptide in treating COVID-19}

Jonathan C. Javitt, MD, MPH' $\mathbf{1}^{\mathbf{1 , 2 , 3}}$

Fifty years ago, Nature published a short report entitled "Potent peripheral and splanchnic vasodilator peptide from normal gut," published by two young scientists working at the Karolinska Institute (Said, Mutt, 1970). Their discovery of Vasoactive Intestinal Peptide (VIP) led to five decades of research into a potent natural anti-cytokine that may have unique potential to block pathways of cell death, particularly those that affect the pulmonary Alveolar Type II cell in SARS-CoV-2 infection.

In the 100 years since the Spanish Flu caused more wartime deaths than combat, no effective drug has been developed to prevent mortality from viral-induced Acute Lung Injury (ALI). The primary cause of death in COVID-19 infection is generally described as Acute Respiratory Distress Syndrome (ARDS), caused by ALI. The injury is generally attributed to cytokine storm - i.e. a massive release of inflammatory cytokines as viral particles infect and then cause rupture of pulmonary epithelium cells. Mortality rates as high as $78 \%$ are being reported in association with COVID-19-related ARDS, despite mechanical ventilation and bestavailable intensive care. There is increasing recognition that this lethal pulmonary injury may be driven by loss of the surfactant that is secreted by pulmonary alveolar type 2 cells that express Angiotensin Converting Enzyme 2 (ACE2) surface receptors to which the SARS-CoV-2 virus binds (Mason 2020). 


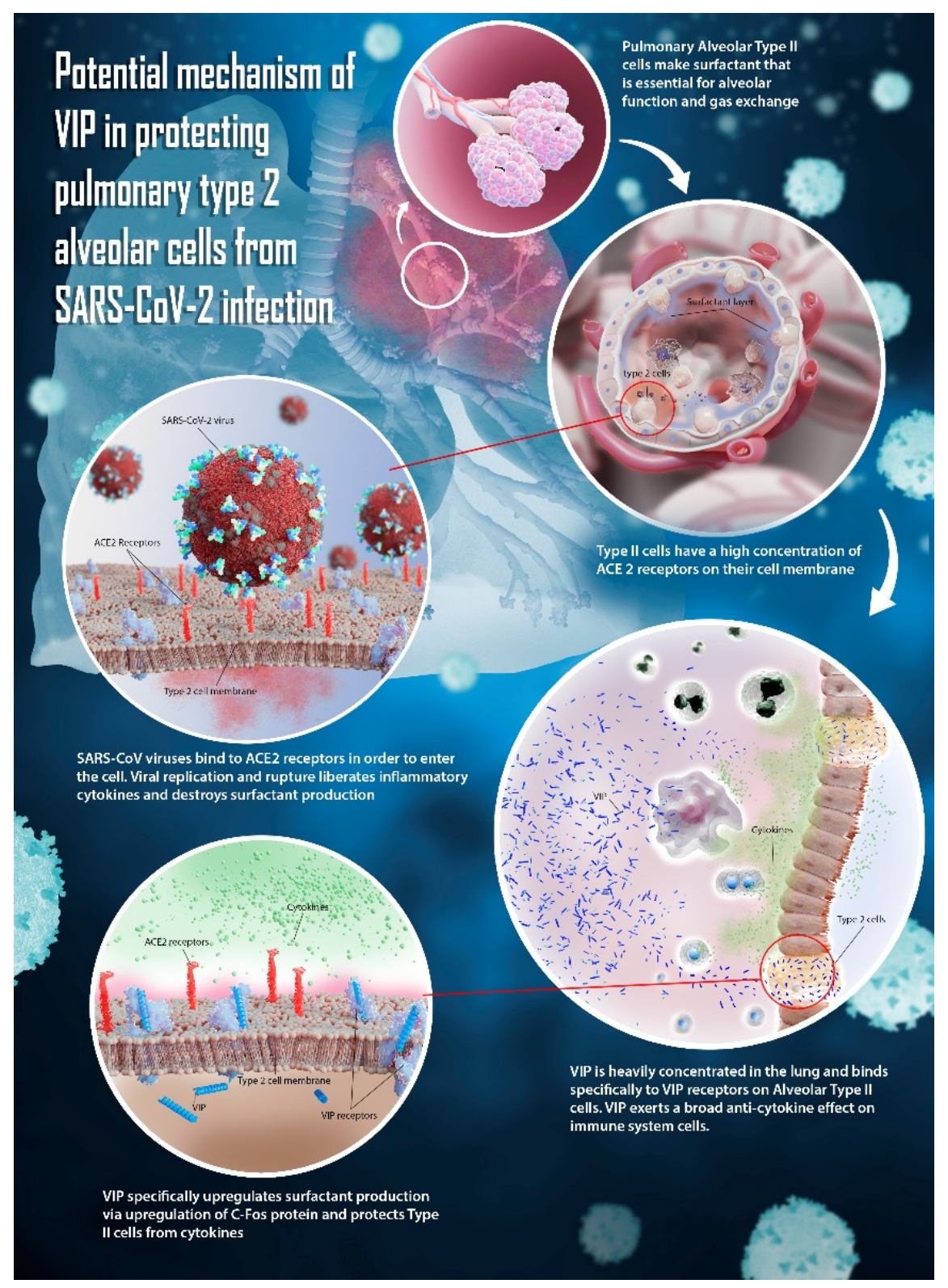

Our purpose is to offer a perspective on why Vasoactive Intestinal Peptide (VIP) and future long-acting derivatives of VIP may prove to be of therapeutic value in the arsenal of drugs currently proposed to treat COVID-19 and subsequent corona virus outbreaks and why previous formulation and intellectual property barriers that impeded its commercial development may be offset by overwhelming public health need. These topics are relevant in light of two FDA multicenter clinical trials that have now been initiated to treat COVID-19 patients with a formulation of Aviptadil, a synthetic form of human VIP (www.clinicaltrials.gov NCT 04311697 and NCT 04360096). While the perspective offered is clearly that of a commercial enterprise, the research cited was primarily performed without industry support.

In brief, we believe that Aviptadil (a synthetic form of human VIP) may uniquely target the pathways that are attacked by the SARS-CoV-2 virus, resulting in Acute Lung Injury (ALI), and lead to death from Acute Respiratory Distress Syndrome (ARDS) in COVID-19. 
Research into VIP's mechanisms of action is a relic of an older era in biology, when researchers focused on cellular pathways and genomics was not yet a word. Although VIP was once viewed as a promising drug and substantial resources were invested in elucidating its pharmacokinetics, toxicology, and safety pharmacology, pharmaceutical companies found it challenging to administer, given the need for inhaled or IV administration and challenging to formulate. Pulmonary drugs are notoriously difficult to develop, given regulatory requirements for long-term inhaled toxicology studies in multiple species, including primates (Tepper 2016). FDA has asserted that these preclinical toxicology requirements must be observed in the case of candidate drugs to treat COVID-19. VIP, on the other hand, completed four-species toxicology and safety pharmacology studies in both intravenous and inhaled dosage forms but did not proceed to the market for lack of a compelling clinical target. Phase 2 trials in sarcoidosis (Prasse 2010), pulmonary hypertension (Leuchte 2008), pulmonary fibrosis, and allergy/asthma suggest that VIP has no major toxicities when inhaled at doses of $300 \mu \mathrm{g} /$ day and that the toxic dose is at least $25 \mathrm{x}$ higher.

Vasoactive Intestinal Peptide (VIP) was first proposed as a modulator of lung inflammation by Said (Said 1988, 1991). VIP is known to have a beneficial effect in numerous models of lung injury (table 1) at the above doses and has shown clinical effects in clinical trials of Acute Respiratory Distress Syndrome (ARDS) and Sarcoid, meaningful reduction in TNF- $\alpha$ and CD4/CD8 ration was seen in sarcoid (Prasse 2010).

Table 1: Effect of VIP in experimental models of acute lung injury

\begin{tabular}{lll}
\hline Species & Etiology of lung injury & References \\
\hline Rat & NDMD induced lung injury w/ arginine & Said 1996, Said \& Dickman 2000 \\
Rat & Xanthine/xanthine oxidase-induced lung injury in perfused lungs & Berisha 1990, Misra 1990 \\
Guinea Pig & Paraquat (methyl viologen) & Pakbaz 1993, Said \& Dickman 2000 \\
Rat & Hydrochloric acid induced pulmonary edema & Foda 1988 \\
Sheep & Intravenous infusion of platelet-activating factor & Pakbaz 1988 \\
Dog & Intravenous infusion of platelet-activating factor & Pakbaz 1988 \\
Guinea Pig & Phospholipase C & Pakbaz 1991 \\
Rat & Cobra venom factor model of septic shock & Mulligan 1992 \\
\hline
\end{tabular}

During the years that were invested in preclinical, particularly inhaled toxicology studies, shifting priorities within the pharmaceutical industry combined with lack of composition of matter patent protection rendered VIP a less than compelling candidate for commercialization.

Until now...

Suddenly, the human race is threatened by a pulmonic virus that attacks the same cells in the lung that VIP uniquely supports and protects. Multiple investigators have confirmed that the SARS-CoV family of viruses selectively attack pulmonary Alveolar Type II (ATII) cells because of their ACE2 receptors, in contrast to other pulmonary epithelial cells. The ATII cells manufacture surfactant that is essential to gas exchange in the alveolus (Mason 2020). For those who don't think about pulmonary physiology every day, remember that epithelial cells die almost immediately upon exposure to air. That's why corneal abrasions occur as soon as the pre-corneal tear film is damaged and why people who sleep with their mouths open wake up with a "scratchy" throat. The pulmonary epithelium is the only epithelial surface that is constantly exposed to air. We can close our eyes and our mouths, but not our lungs. The patency of the alveolus and the viability of its vulnerable epithelial cells is maintained by an aqueous/surfactant layer that enables gas exchange. However the integrity of this layer requires a film of surfactant to maintain surface tension.

VIP is a potent anti-cytokine in the lung that provides key defense against numerous forms of acute lung injury. Although named (or mis-named) for the tissue in which it was first isolated, VIP is produced by neuroendocrine cells throughout the body and by T-lymphocytes, B-lymphocytes, and macrophages. VIP is highly localized in the lung (Virgolini 1995) but is a widely distributed immunomodulator with protective effects in heart, thyroid gland, kidney, immune system, urinary tract and genital organs. Early 
COVID-19 lung injury is characterized by a remarkable degree of hypoxia in the absence of overwhelming pneumonia, suggesting a primary injury to the pulmonary gas-exchange mechanism. Patients frequently report "crackling sounds" while attempting to breath, consistent with the theory that loss of surfactant and alveolar gas exchange is an early hallmark of COVID-19. VIP is the body's primary defense against cytokine injury in the lung and elsewhere. Unlike synthetic anti-cytokines, such as anti-IL6 drugs, VIP is shown to have a specific role in preserving surfactant production in the lung ( $\mathrm{Li} 2004$, Li 2010) and in protecting type 2 alveolar cells. Accordingly, VIP and longer acting modifications of VIP have been proposed in the past as respiratory therapeutics (Mathioudakis 2013).

As we learn more about the lethal consequences of COVID-19 infection, cardiac and other non-pulmonary effects are increasingly reported. In the lung, VIP attenuates, delays or prevents acute lung injury in various experimental models of ARDS, both in isolated lungs as well as in vivo. VIP protects the heart and other vital organs against oxidative injury, has anti-inflammatory activity against a variety of inflammatory mediators and is anti-apoptotic. There is ample evidence to suggest a potential role of VIP in preventing apoptosis, reducing inflammation and endotoxemia, and maintaining surfactant production in the face of lung injury.

\section{COVID-19 and Immune Response:}

Coronavirus pathophysiology in humans has been studied since the 2004 SARS epidemic, where pulmonary complications were traced to release of proinflammatory cytokines occurred, including IL-6, IL-12, and TNF$\alpha$. Patients with SARS-CoV-2 pneumonia admitted to an ICU had higher plasma levels of cytokines including IL-6, IL-2, IL-7, IL-10, granulocyte-colony stimulating factor (G-CSF), interferon- $\gamma$-inducible protein (IP10), monocyte chemoattractant protein (MCP1), macrophage inflammatory protein 1 alpha (MIP1A), and TNF$\alpha$ (Wong 2004). Studies on MERS-CoV, demonstrated marked upregulation of cytokine genes of IL-6, IL-1 $\beta$, and IL-8 (Channappanaver 2017). This phenomenon is now widely called a "cytokine storm." More recent data, point to the specific attack of the virus on ACE2 receptors of the type 2 alveolar cells with selective death of those cells.

In recent years, interleukin 6 (IL-6) blocking drugs and biologics have been developed to treat arthritis, inflammatory bowel disease, and other autoimmune conditions. While some have suggested that blockade of IL-6 alone may block the cytokine storm in COVID-19, failures of IL-6 specific antagonists in recent clinical trials suggest that a broader anti-cytokine strategy may be needed. IL-6 is only one of numerous cytokines that are upregulated and attack the pulmonary epithelium.

If the mechanism of ALI in SARS-CoV-2 infection was driven by cytokine-induced inflammation alone, steroids and other anti-inflammatory drugs might be expected to have some salutary effect. Lung injuries seen in COVID-19 are increasingly recognized as similar to those in premature infants where loss of surfactant, secreted by alveolar type II cells leads to demise of premature infants despite mechanical ventilation. The SARS-CoV-2 virus is known to enter cells via binding to ACE2 receptors on the cell surface and those receptors are predominantly found on the Alveolar type II (ATII) cells. Moreover, VIP receptors are preferentially expressed on ATII cells and VIP is shown to prevent their apoptosis in models of lung injury (Onoue, 2004).

\section{Scientific Rationale for VIP effect in COVID-19}

\section{Preservation of pulmonary tissue:}

Three studies validate the protective role of VIP on isolated and transplanted lung models. Isolated rat lungs stored in VIP- containing solutions had significantly more normal shaped mitochondria, less mitochondrial edema, less distortion of mitochondrial cristae, thinner basal lamina, and less aggregation of nuclear chromatin than lungs stored in control solutions (Alessandrini 1993). VIP significantly delayed the onset of edematous lung injury in isolated perfused rat lungs - in control solution after 213 minutes, in Aviptadil solution after 349 minutes (Pakbaz 1994). VIP was effective in preventing ischemia-reperfusion injury in an in vivo rat lung transplantation model as demonstrated by improved pulmonary function (Nagahiro 1998).

Inhibition of Apoptosis: One of the main features of coronavirus lung injury is destruction of the alveolar 
epithelium, with severe damage to the alveolar capillary barrier and major increase in alveolar capillary permeability. Alveolar epithelium of patients who die from lung injury is notable for evidence of DNA fragmentation. Extensive alveolar epithelial cell apoptosis is found in murine models of lipopolysaccharideinduced lung injury (Matute-Bello 2003). There are two independent cell death pathways involved in the destruction of lung cells in ARDS - the Fas/Fas ligand and the perforin/granzyme system (Hashimoto 2000). Several lines of evidence point to the Fas/Fas ligand system as an underlying mechanism responsible for the epithelial cell apoptosis in acute lung injury and ARDS (Albertine 2002). The Fas/Fas ligand system is comprised of the cell membrane surface receptor Fas (CD95) and its ligand. Alveolar and airway epithelial cells express Fas on their surface and the expression of Fas in epithelial cells increases in response to inflammatory mediators. Soluble Fas ligand is present in bronchio-alveolar lavage fluids of patients with early ARDS and reaches higher concentrations in the lung fluids of patients who die. This detected Fas ligand is biologically active and causes apoptosis in normal human lung epithelial cells (Matute-Bello 1999). VIP is a potent inhibitor of Fas ligand expression and has been shown to inhibit Fas ligand-mediated cell death (Delagado 1998,1999).

The second cell death pathway relevant to ARDS and COVID-19 lung injury acts via degranulation of serine proteases, granzymes, together with the pore-forming protein, perforin, to induce rapid death of the target cells (Hashimoto 2000). VIP is a proven inhibitor of activation-induced perforin, as well as of granzyme B and therefore actively contributes to the reduction of deleterious proinflammatory and cell death-inducing processes, particularly in the lungs (Sharma 2006). Caspase-3, has been identified as a key mediator of apoptosis in mammalian cells via its role in cleaving a variety of substrate proteins and inducing DNA fragmentation. In animal models of ALI, caspase activity is significantly increased compared to its activity in normal lungs and VIP is shown to suppress caspase activation (Said \& Dickman, 2000). Finally, NMDA induced experimental lung injury is associated with downregulation of the anti-apoptotic gene bcl-2 and this downregulation is reversed is preserved in lungs treated with VIP (Said \& Dickman, 2000).

Inflammation: During the early phase of ALI, the lung is the site of an intense inflammatory process with sequential activation of cytokines, chemokines, and secretion of proteases, as well as concomitant collagen synthesis. Evidence of an acute inflammatory reaction in the alveolar-microvascular area also includes recruitment and activation of inflammatory cells, increased production of toxic oxygen metabolites, nitric oxide, and a protein rich exudate in the air spaces. A key regulator involved in a variety of these processes is the nuclear transcription factor NF-kB. This protein is normally located in cell cytoplasm and bound to an inhibitory protein $\mathrm{IkB}$ in an inactive state. Inducers of NF-kB activation trigger a cascade of reactions ending in liberation of NF-kB from IkB. NF-kB trans-locates into the cell nucleus where it binds to the promoter sequences of many defense and immune response genes thereby inducing their expression - for example the expression of tumor necrosis factor alpha $(\mathrm{TNF}-\alpha)$. VIP has been shown to inhibit NF-kB activation in numerous animal models of acute lung injury, while preventing or attenuating the injury. Delgado 1998).

Effect of VIP on Surfactant Production: A pathologic hallmark of the ALI/ARDS is the damage to the surfactant-producing alveolar type II cells (Mossel 2008). These cells are characterized by Angiotensin Converting Enzyme 2 (ACE2) receptors on the cell surface and, therefore, may be particularly susceptible to SARS-CoV-2 virus infection. Studies have demonstrated high density VIP binding sites on rat type II cells (Onoue, 2004). Li demonstrated in rat lung explants that VIP increased the incorporation of methyl-choline into phosphatidylcholine - the major component of the pulmonary surfactants - by enhancing the activity of the enzyme choline-phosphate cytidylyltransferase (Li 2004). VIP upregulates C-Fos protein expression in cultured type II alveolar cells, which is instrumental in promoting synthesis of pulmonary surfactant phospholipids ( $\mathrm{Li} 2007$ ) and induces surfactant protein A expression in ATII cells through activation of $\mathrm{PKC} / \mathrm{c}-$ Fos pathway.

\section{Conclusion:}

In the 50 years that have elapsed since the discovery of VIP (Said 1970), numerous mechanisms of pulmonary protection have been elucidated in connection with VIP and efficacy signals have been seen in association with ARDS, Sarcoid, and perhaps other human lung conditions. It may be that VIP has not advanced to 
approval as a human pulmonary drug because of the need for either IV or inhaled administration and because of its relatively short half-life, requiring multiple daily doses. However, we now face a lethal viral infection that specifically attacks the ATII cells that are essential for the continuation of human life. Those are the cells that bind VIP and rely on VIP to drive the production of surfactant. This highly specific role of VIP in the lung may be key to combating the lethal effects of SARS-CoV-2 infection. Unlike synthetic anti-cytokine and interleukin drugs, VIP has no known human toxicity,. COVID-19 may represent a unique circumstance in which the biologic potential of VIP offsets any challenges to its route or frequency of administration, its commercial attractiveness (or lack thereof) due to lack of patent protection, and its remarkably low cost compared to more "modern" drugs.

Illustration credit: Nicolás Fernández

\section{Acknowledgement}

The author acknowledges the scientific input of Yves Sagot, PhD, Norman B. Javitt, PhD, MD, and Matthew J. Javitt, MD, in the preparation of this work.

Author Affiliations:

1. CEO, NeuroRx, Inc., Radnor, PA

2. Adj. Professor, Johns Hopkins School of Medicine, Baltimore, MD

3. Senior Fellow, National Security Health Policy Center, Potomac Institute for Policy Studies, Arlington, VA

\section{Disclosure:}

The author is an employee and shareholder of a company that is developing VIP for commercial use.

\section{References}

Albertine, KH, Soulier MF, Wang Z, et. al. Fas and Fas Ligand Are Up-Regulated in Pulmonary Edema Fluid and Lung Tissue of Patients With Acute Lung Injury and the Acute Respiratory Distress Syndrome. Am J Pathol 2002;161(5):1783-1796.

Alessandrini, F., Thakkar, M., Foda, H.D., Said, S.I., Lodi, R., Pakbaz, H., and Schraufnagel, D.E. Vasoactive intestinal peptide enhances lung preservation. Transplantation 1993;56:964-973.

Berisha, H., Foda, H., Sakakibara, H., Trotz, M., Pakbaz, H., and Said, S.I. Vasoactive intestinal peptide prevents lung injury due to xanthine/xanthine oxidase. Am. J. Physiol 1990;259:L151-L155.

Channapanaver R, Perlman S. Pathogenic human coronavirus infections: Causes and consequences of cytokine storm and immunopathology. Semin Immunopathol 2017;39(5):529-539.

Delgado, M, Martinez C, Pozo D, Calvo JR, Leceta J, Ganea D, Gomariz RP. Vasoactive intestinal peptide (VIP) and pituitary adenylate cyclase-activation polypeptide (PACAP) protect mice from lethal endotoxemia through the inhibition of TNF-alpha and IL-6. J Immunol. 1999;162:1200-1205.

Delgado M, Munoz-Elias EJ, Kan Y, Gozes I, Fridkin M, Brenneman DE, Gomariz RP, Ganea D. Vasoactive intestinal peptide and pituitary adenylate cyclase-activating polypeptide inhibit tumor necrosis factor alpha transcriptional activation by regulating nuclear factor-kB and cAMP response element-binding protein/cJun. J. Biol. Chem. 1998;273:31427-31436.

FDA Guidance for Industry: COVID-19 Public Health Emergency: General considerations for Pre-IND meeting requests for COVID-19 related drugs and biological products. May 2020

Foda, H.D., Iwanaga, T., Liu, L.-W., and Said, S.I. Vasoactive intestinal peptide protects against HCl-induced pulmonary edema in rats. Ann NY Acad Sci 1988;633-636. 
Hashimoto S, Kobayashi A, Kooguchi K, et. al. Upregulation of two death pathways of perforin/granzyme and FasL/Fas in spetic acute respiratory distress syndrome. Am J Respir Crit Care Med 2000, 161(1):237-243.

Leuchte HH, Baezner C, Baumgartner RA, et. al. Inhalation of vasoactive intestinal peptide in pulmonary hypertension. Eur Respir J 2008;32:1289-1294.

Li, L., Luo, Z.Q., Zhou, et. al. Effect of vasoactive intestinal peptide on pulmonary surfactants phospholipid synthesis in lung explants. Acta Pharmacol. Sin. 2004;25:1652-1658.

Li L, She H, Yue S, et. al. Role of C-Fos gene in vasoactive intestinal peptide promoted synthesis of pulmonary surfactant phospholipids. Regul Pept 2007;140(3):117-124.

Li L, Hua S, Yue S, Luo Z, et. al., Vasoactive intestinal polypeptide induces surfactant protein A expression in ATII cells through activation of PKC/c-Fos pathway. Peptides 2010;31(11):2016-2051

Mason R. Pathogenesis of COVID-19 from a cell biologic perspective. Eur Respir J. April 9 Epub ahead of print. https://www.ncbi.nlm.nih.gov/pmc/articles/PMC7144II60/

Mathioudakis AG, Chatzimavridou-Grigoriadou V, Evangelopoulou E, Mathioudakis GA. Vasoactive Intestinal Peptide Inhaled Agonists: Potential Role in Respiratory Therapeutics. Hippokratia 2013;17(1):12-16

Matute-Bello G, Liles WC, Steinberg KP, Kiener PA, Mongovin S, Chi EY, Jonas M, Martin TR. Soluble Fas ligand induces epithelial cell apoptosis in humans with acute lung injury (ARDS). J Immunol 1999;163(4):2217-2225.

Matute-Bello G, Martin T. Science Review: Apoptosis in acute lung injury. Crit Care 2003;7(5):355-358

Misra BR and Misra HP. Vasoactive intestinal peptide, a singlet oxygen quencher. J. Biol. Chem 1990;265:15371-15374.

Mossel EC, Wang J, Jeffers S, et al. SARS-CoV replicates in primary human alveolar type II cell cultures but not in type I-like cells. Virology 2008;372:127-135.

Mulligan MS, Varani J, Warren JS, Till, G.O., Smith, C.W., Anderson, D.C., Todd, R.F., III, and Ward, P.A. Roles of beta 2 integrins of rat neutrophils in complement- and oxygen radical-mediated acute inflammatory injury. J. Immunol. 1992;148:1847-1857.

Nagahiro I, Yano M, Boasquevisque CH, Fujino, S, Cooper, JD, and Patterson, GA. Vasoactive intestinal peptide ameliorates reperfusion injury in rat lung transplantation. J. Heart Lung Transplant. 1998;17:617621.

Onoue S, Ohmori Y, Endo K, Yamada S, Kimura R, Yajima T. Vasoactive intestinal peptide and pituitary adenylate cyclase-activating polypeptide attenuate the cigarette smoke extract-induced apoptotic death of rat alveolar L2 cells. Eur. J. Biochem. 2004;271: 1757-1767.

Pakbaz H, Berisha H, Sharaf H, Foda HD, Said SI. VIP enhances and nitric oxide synthase inhibitor reduces survival of rat lungs perfused ex vivo. Ann. N. Y. Acad. Sci. 1994;723:426-428.

Pakbaz H, Foda HD, Berisha HI, Trotz, M, Said SI. Paraquat-induced lung injury: prevention by vasoactive intestinal peptide and related peptide helodermin. Am. J. Physiol 1993;265:L369-L373.

Prasse A, Zissel G, Lützen N, Schupp J, Schmiedlin R, Gonzalez-Rey E, Rensing-Ehl A, Bacher G, Cavalli V, Bevec D, Delgado M, Müller-Quernheim J.. Inhaled vasoactive intestinal peptide exerts immunoregulatory effects in sarcoidosis. Am J Respir Crit Care Med. 2010;182:540-8

Petkov V, Mosgoeller W, Ziesche R, Raderer M, Stiebellehner L, Vonbank K, Funk GC, Hamilton G, Novotny C, Burian B, Block LH. Vasoactive intestinal peptide as a new drug for treatment of primary pulmonary hypertension. J. Clin. Invest 2003;111:1339-1346. 
Said SI, Mutt V. Potent peripheral and splanchnic vasodilator peptide from normal gut. Nature. 1970; 225: 863-864.

Said SI. Vasoactive intestinal peptide in the lung. Ann NY Acad Sci 1988;527:450-464

Said SI. VIP as a modulatory of lung inflammation and airway constriction Am Rev Respir Dis 1991;143:S22S24.

Said SI, Dickman KG. Pathways of inflammation and cell death in the lung: modulation by vasoactive intestinal peptide. Regul. Pept. 2000;93:21-29.

Sharma V, Delgado M, Ganea D. Granzyme B, a new player in activation-induced cell death is downregulated by vasoactive intestinal peptide in Th2 but not Th1 effectors. J Immunol 2006;176(1):97-110.

Tepper JS. Symposium Summary: Breathe In, Breath Out, It's Easy. What you need to know about developing inhaled drugs. Int J Toxicol, 35(4):376-392

Virgolini I, Kurtaran A, Raderer M, et. al. Vasoactive Intestinal Peptide Receptor Scintigraphy. J Nucl Med 1995:36(10):1732-1739

Wong CK, Lam CWK, Wu AK, et al. Plasma inflammatory cytokines in severe acute respiratory syndrome. Clin Exp Immunol 2004:136(1):95-103. 